\title{
LEAN TOOLS APPLIED TO A SHIPBUILDING PANEL LINE ASSEMBLING PROCESS
}

UDC 629.5.081

Professional paper

\begin{abstract}
Summary
To improve the shipbuilding process and obtain a more cost-effective production, several approaches are used today. The state of the art approach is based on newer production technologies, mainly steel cutting and welding technologies, which allows to improve the quality of the products and reduce the production time. Other approach, not so applied, is based on the re-organization some shipbuilding stages, applying some production improvement tools, like the Lean approach. The panel assembly line stage of the shipbuilding process is a key phase of the production sequence due to its relation with the remaining shipbuilding stages, essentially framed in the ship's block construction sequence, and its characteristics make it an accessible shipbuilding stage to apply the Lean approach tools. The Lean tools can be applied with a wide range of minuteness and on variable settings. The present paper analyses a rather simple modification on the panel line assembling process sequence, achieved through the application of some key concepts of the Lean approach. For the verification of the times and costs benefits due to the application of the proposed modification, a graphic interface tool was developed, allowing to analyse the costs and times results of the panel line production process.
\end{abstract}

Key words: shipbuilding; panel line; lean

\section{Introduction}

The production competition imposed on the European shipbuilding industries, due to better developed production processes of the Far-East shipbuilding companies, force new solutions to be studied and applied in the European shipyards. The state of the art solution to reach a cost-effective ship production tends to emphasize new technical solutions, mainly new and better cutting and welding technologies, as quoted by Gordo et al. [1]. However, a parallel approach to improve the production process concerns the use of process improvement methodologies, as the Lean methodology. The Lean methodology application covers a wide range of minuteness and can be applied on variable settings and production stages. The present paper concerns a rather simple analysis and application of some Lean methodology key concepts on one of the most important production stage of the shipbuilding process: the panel assembly line sequence. The panel assembly line is one of the most straightforward stages, framed in the complex shipbuilding process, to apply such production improvement tools, due to its simplicity and well-established sequence of actions and workstations. 


\section{Background}

The Lean methodology was developed in Japan after $2^{\text {nd }}$ World War, and was also known as Toyota Production System (TPS). As stated by Taichii Ohno [2], one of the key TPS's goals is to identify and eliminate the seven major wastes typically found in mass production: overproduction, waiting, motion, transport, over processing, inventory and defects. During the 90's the Lean principles were imported to the shipbuilding studies and applied in the industry. The importance and benefits of the application of Lean methodology in the shipbuilding industry was stressed by Liker \& Lamb [3] and Storch \& Lim [4]. Kolich et al. [5, 6] developed a significant set of studies on the subject of application of Lean methodologies in the shipbuilding process, some of them inspecting with more detail such methodology application on the panel assembly line.

Motivated by these works, the present paper aims to deepen the demonstration of economic advantages due to the application of Lean methodology on the panel assembly line, by developing a graphic interface tool to compute the times and costs of the panel assembly line manufacturing process before and after the application of rather simple modifications in the production sequence.

Regarding shipbuilding times and costs analysis models and the panel assembly line manufacturing, which had significant importance for the present paper, some investigations were recently carried out, respectively, by Leal \& Gordo [7] and by Oliveira \& Gordo [8].

\section{Panel assembly line analysis tool}

The understanding of the times and costs effects of modifications on the panel assembly line manufacturing stages, a graphical interface tool (PALIAN, Panel Assembly LIne ANalysis) [9] was created, as shown in Figure 1.

PALIAN allows the user to specify the times and costs settings for each main activity as presented in Figure 2, of the four panel assembly line stages considered: Plate cutting; buttwelding; stiffeners assembling; and stiffeners welding. The user is also free to detail the set of flat panels which are to be considered during the computations.

PALIAN generates an output file with the times and costs values of the classical approach and Lean improved proposed approach allowing for comparison.

\section{LEAN methodology on the panel assembly line}

The improvement of the manufacturing process can only be done by the understanding and interpretation of the original sequential flow of the production process, and then apply manufacturing improvement methodologies in the production sequence.

\subsection{Original panel assembly line manufacturing process}

The original panel assembly line manufacturing process is based on Oliveira \& Gordo [8], where the production sequence is quite well demonstrated. Figure 3 illustrates the original panel assembly line sequence flow production.

The $1^{\text {st }}$ workstation consists on the plate blanket fabrication, through the one side submerged arc welding technology of the panel's plates, hence not needing to turn over the plates. This workstation can be divided in 5 main stages: align and tack welding of the plates; SAW (Submerged Arc Welding) preparation; SAW of the butt weld; weld quality control; possible re-welding of some weld fragment. That butt welding process' stages are repeated for as many plate joins that the panel presents. 


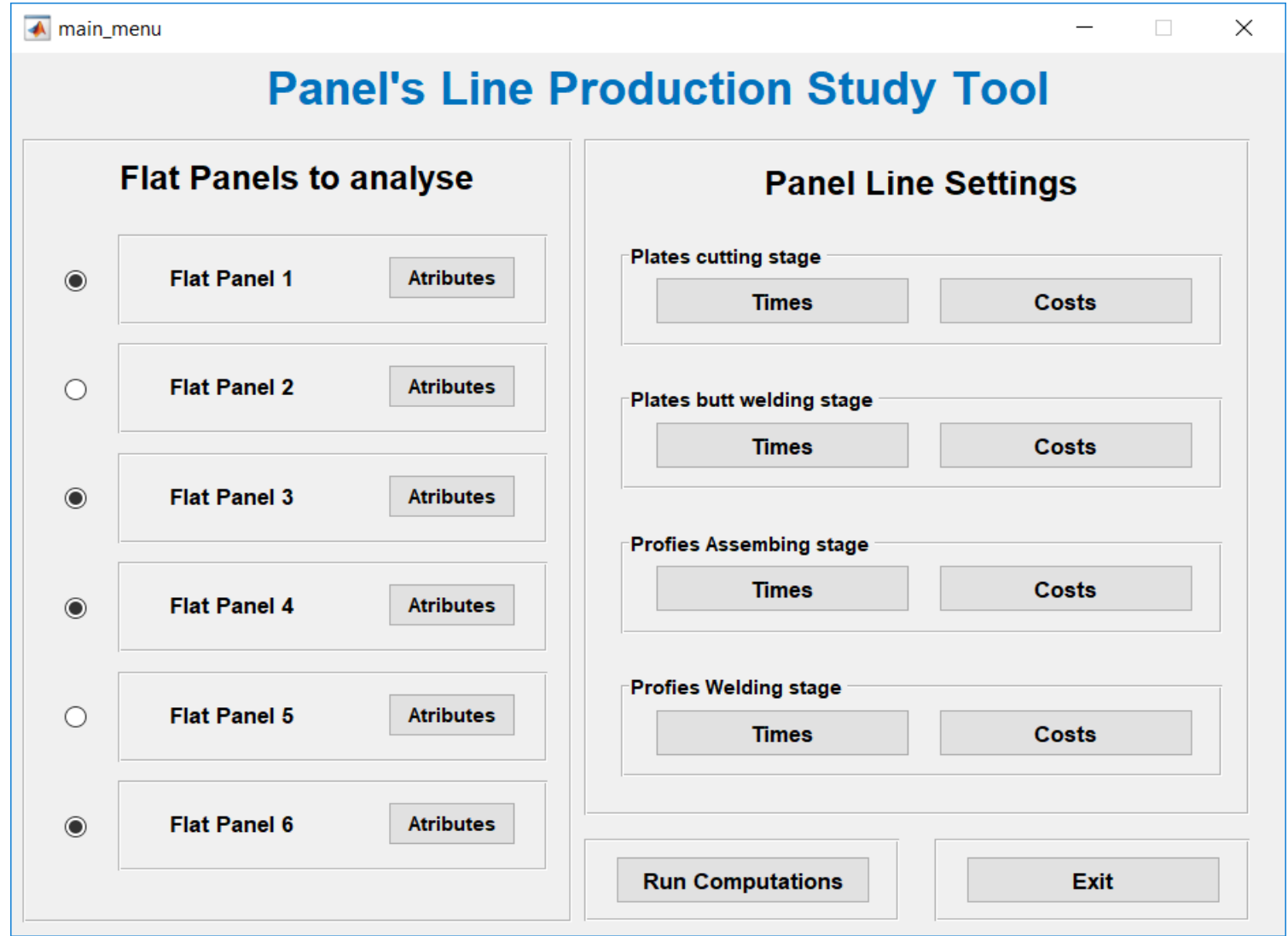

Figure 1 Main menu of the developed program

A panel_line_butt_welding_times

\section{Panel Line Settings - Plates butt welding stage - Times}

Butt Welding

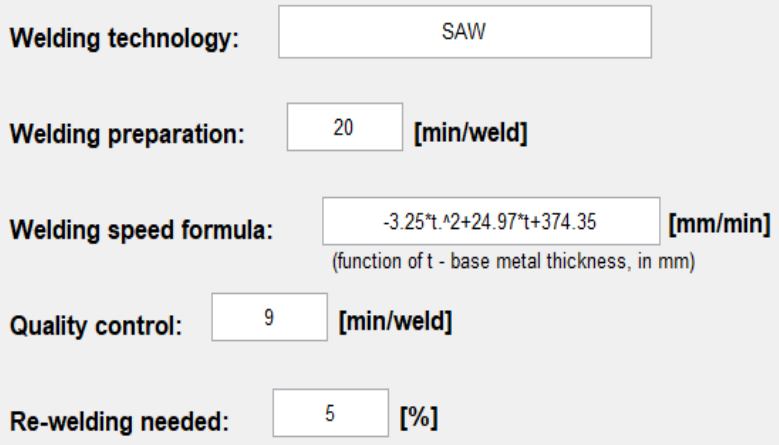

Tag Welding

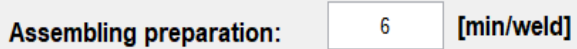

Tag-welding speed:

2000 [mm/min]

Update values

Update

Figure 2 Graphic user interface for the butt weld workstation times values input

The $2^{\text {nd }}$ workstation is responsible for the automatic oxy-fuel cutting and marking of the previously assembled plate blanket. The workstation can be summarized in the following stages: automatic cutting preparation; automatic marking; automatic cutting; manual cutting; dimensional control.

The $3^{\text {rd }}$ workstation consists on the manual assembling of the stiffeners on the plate blanket, and can be summarized in the following stages: Distribution of the stiffeners, tagwelding of the stiffener and angular control. 


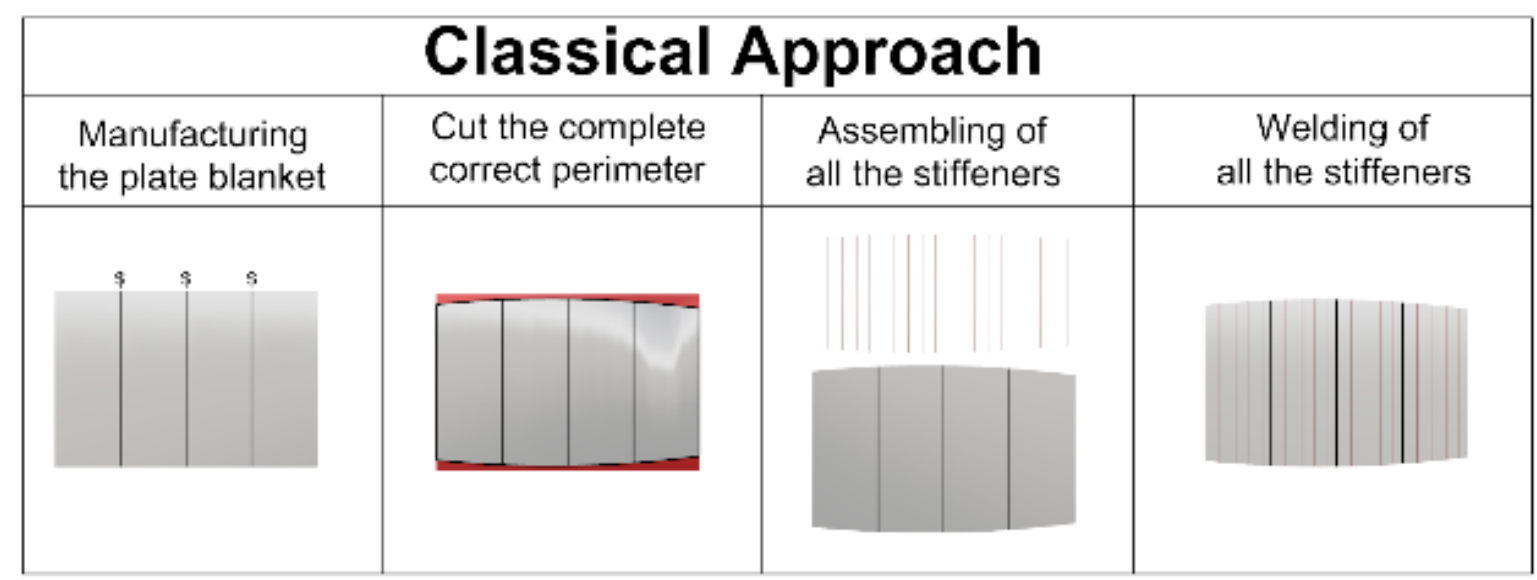

Figure 3 Panel assembly line classical approach sequence

The $4^{\text {th }}$ workstation due the semi-automated GMAW-MAG (Gas Metal Arc Welding Metal Active Gas) welding of the stiffeners, on both sides. In this workstation the welding process can be divided in the following phases: preparation of the welding equipment; preparation of the first side weld; welding of the first side of the stiffener; preparation of the second side weld, i.e., deburring of the tag-welds realized in the third workstation; welding of the second side of the stiffeners; quality control of the weld; possible re-welding of some fragments of the fillet weld.

\subsection{Flat panels to simulate manufacturing}

PALIAN allows to undertake the manufacturing process simulation of the panel assembly line by computing the times and costs, using a set of values defined by the user in the software's graphical interface. The flat panels used in the present paper were part of a new ship built in the Portuguese "WESTSEA Shipyard", and the correspondent panel line construction stages times were obtained by the direct monitorization of the manufacturing process by the authors. The four flat panels considered present the following characteristics:

The first flat panel, with a $7.7 \mathrm{~m}$ width and $7.0 \mathrm{~m}$ length, illustrated in Figure 4, comprehends four plates of $7 \mathrm{~mm}$ thickness, totalizing a cutting length of $34.6 \mathrm{~m}$, and ten stiffeners with thickness of $8 \mathrm{~mm}$ and $10 \mathrm{~mm}$, totalizing $63.0 \mathrm{~m}$ of stiffeners to assemble and weld.

The second flat panel, with $11.1 \mathrm{~m}$ width and $8.6 \mathrm{~m}$ length, presents five plates of $5 \mathrm{~mm}$ thickness, totalizing $49.8 \mathrm{~m}$ of cutting length, and twenty-three stiffeners of $6 \mathrm{~mm}$ thickness, totalizing $129.1 \mathrm{~m}$ of stiffeners to assemble and weld, as shown in Figure 5. The third flat panel, with $12.5 \mathrm{~m}$ width and $10.0 \mathrm{~m}$ length, is made up also with five plates of $5 \mathrm{~mm}$, totalizing 43.8 $\mathrm{m}$ of cutting length, and 23 stiffeners of $6 \mathrm{~mm}$, totalizing $141.3 \mathrm{~m}$, as illustrated in Figure 6 .

The fourth flat panel considered, with $12.6 \mathrm{~m}$ width and $11.5 \mathrm{~m}$ length, presents five plates of $5 \mathrm{~mm}$ thickness, totalizing $62.3 \mathrm{~m}$ of cutting length, and forty-one stiffeners totalizing 237.9 $\mathrm{m}$, Figure 7. 


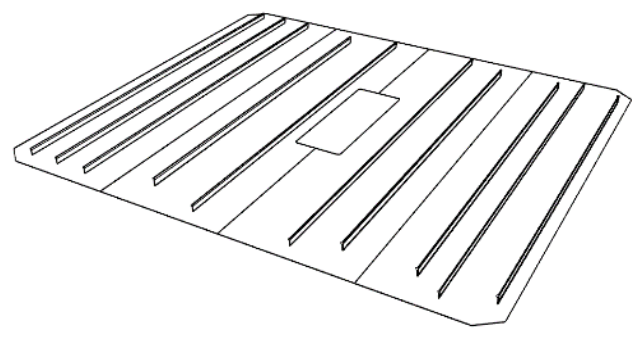

Figure 4 Flat panel 1

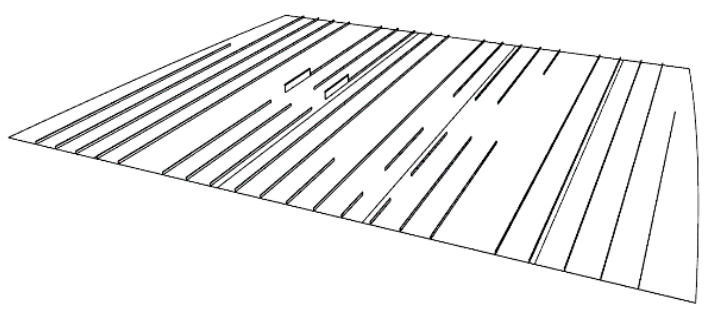

Figure 6 Flat panel 3

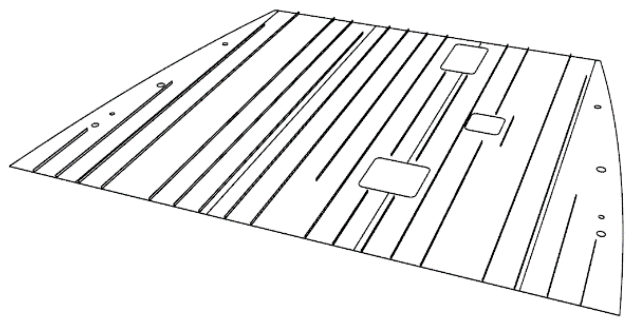

Figure 5 Flat panel 2

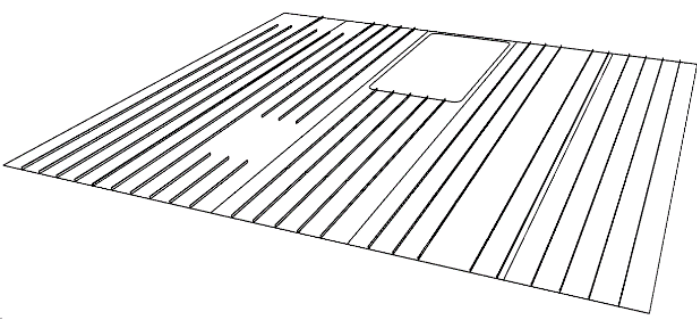

Figure 7 Flat panel 4

\section{Original sequence times results}

PALIAN generated the flow sequence time chart of the manufacturing process, as in Figure 8. Each colour of the time chart is representative of a different flat panel, the first row illustrates the time for the butt welding, the second row illustrates the cutting of the plate blanket, the third one represents the stiffeners assembly, and the last row shows the times for the stiffeners welding.

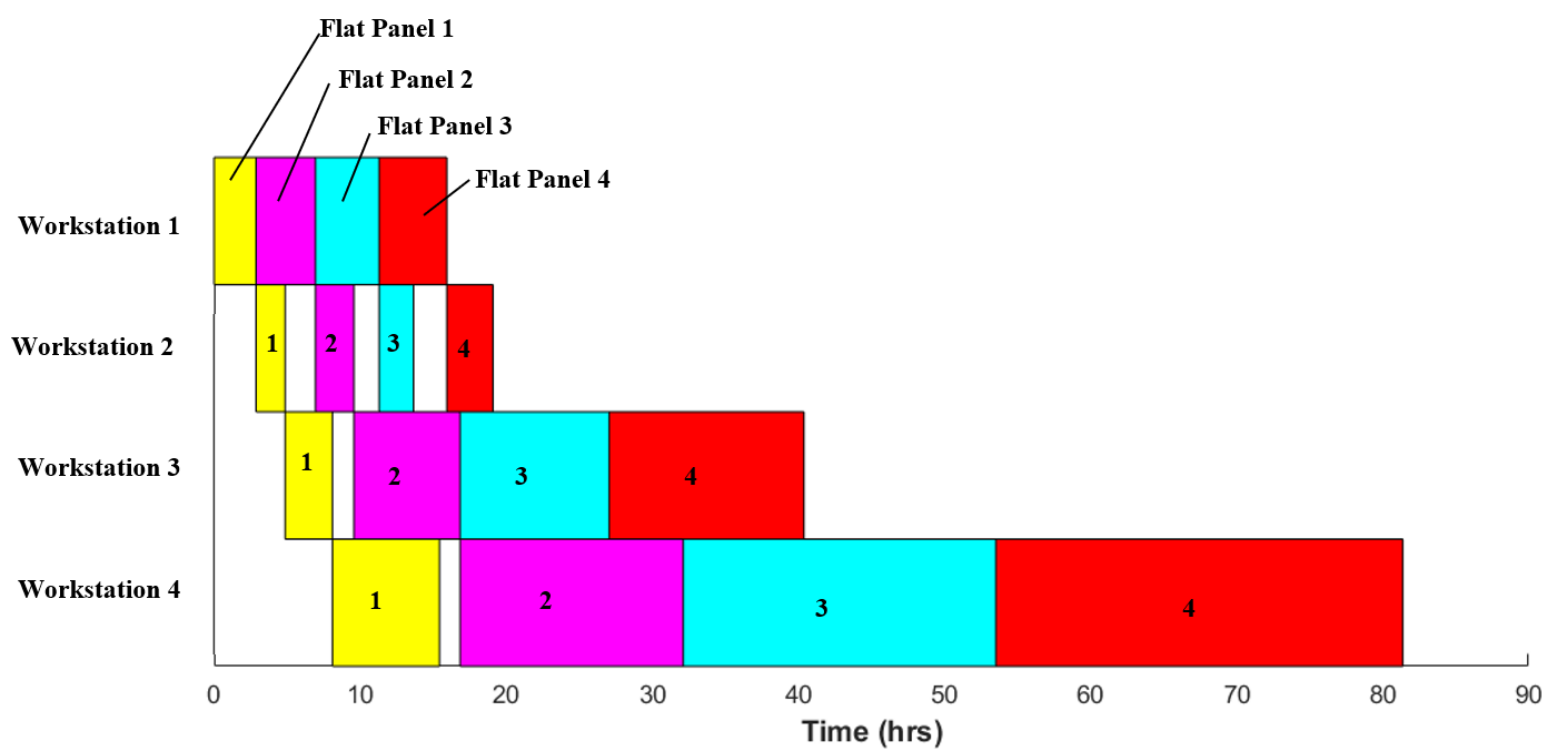

Figure 8 Original sequence time chart

Through the interpretation of the time values obtained, it is possible to generate a handmade value stream map of the original panel assembly line sequence, as shown in Figure 9. The value stream mapping analysis of the production process is a key tool of the Lean methodology and Figure 10 displays the representative meanings of the symbols and notations of the value stream map. 


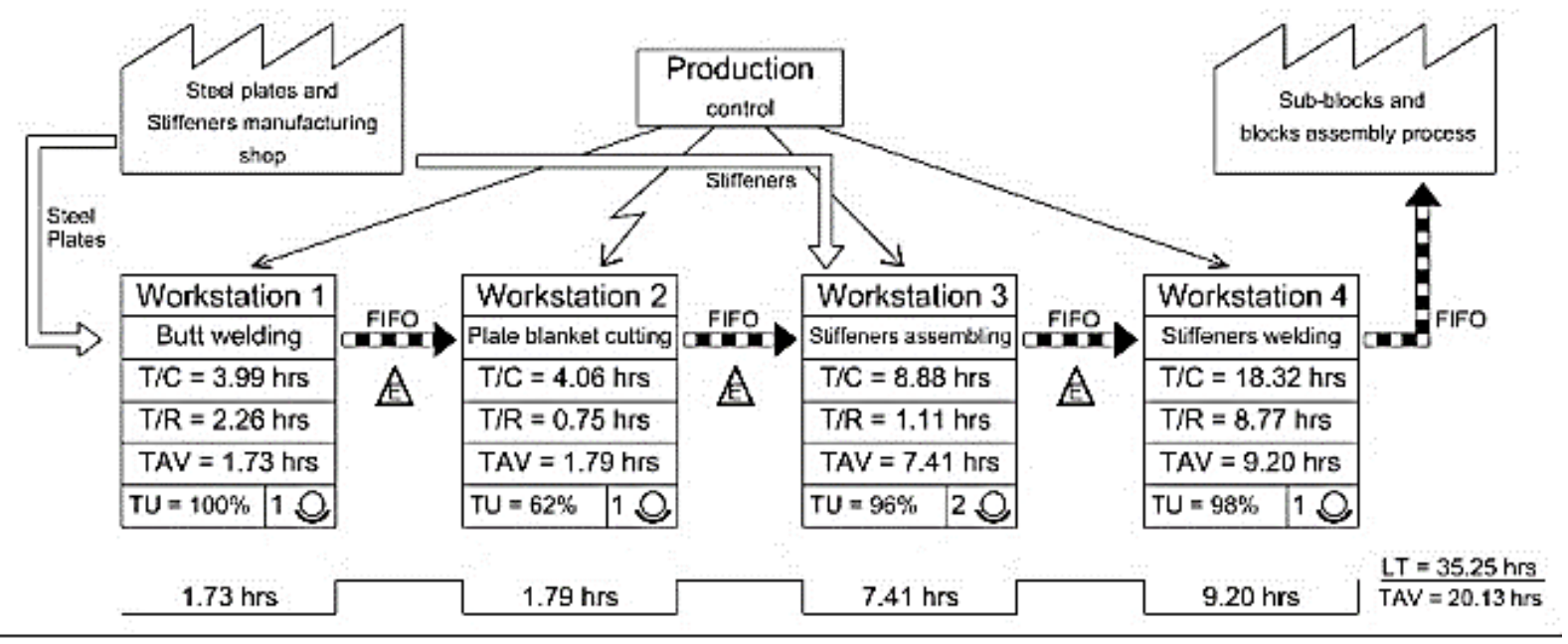

Figure 9 Original sequence value stream map

As demonstrated in the value stream map for the original sequence production flow, we obtain the following ratio of the Lead Time (LT), which translates the time between the beginning of the activity and its completion, over the TAV (Time of Added Value):

$$
\frac{L T_{1}}{T A V_{1}}=\frac{35.25}{20.13}=1.75
$$

\begin{tabular}{|c|c|c|c|}
\hline & Push flow & \multirow{3}{*}{\multicolumn{2}{|c|}{$\begin{array}{l}\text { LT }=\text { Lead time } \\
\text { T/C = Cycle time } \\
\text { T/R = Changeover time } \\
\text { TAV = Time of added value activities } \\
\text { TU - Equipment time use }\end{array}$}} \\
\hline & Pull flow & & \\
\hline & $\begin{array}{l}\text { Number of } \\
\text { workers }\end{array}$ & & \\
\hline $\mathrm{Fl}$ & $\begin{array}{l}\text { First In } \\
\text { First Out }\end{array}$ & $\rightarrow r$ & $\begin{array}{l}\text { Electronic flux } \\
\text { of information }\end{array}$ \\
\hline & $\begin{array}{l}\text { Inventory } \\
\text { queue }\end{array}$ & & $\begin{array}{l}\text { Manual flux } \\
\text { of information }\end{array}$ \\
\hline
\end{tabular}

Figure 10 Value stream map symbols and notations

In order to explain the way some of the values of Figure 9 were computed, it is possible to exemplify that, for the $1^{\text {st }}$ workstation, the Cycle Time (T/C) was obtained by dividing the total time, from the moment of the initiation of the first flat panel until the moment of completion of the last flat panel $(15.96 \mathrm{~h})$, by the number of flat panels (4 panels); the Changeover Time (T/R) was computed by dividing the activities that cannot be categorized as added time values $(9.04 \mathrm{~h})$, not including waiting times, by the number of flat panels; and the Time of Added Value Activities was obtained by dividing the activities that can be categorized as source of added value $(6.92 \mathrm{~h})$ by the number of flat panels.

It is key to stress that considerations of what should be assumed as "added value activities" in the panel assembly line were greatly loose assumptions. Otherwise, the ratio would be expected to be much higher if one would be more precise in such "added value activities" concept. The main goal of the Lean methodology application is to decrease as far as possible the ratio, by reducing the non-value-added activities and eliminating queues in the flow production. 


\section{Change of sequence of the panel assembly line}

By analysing the time chart and respective value stream map of the original sequence manufacturing flow is evident some possible adverse effect of the queue instances on all the stages. Hence, it will be studied the implementation of different manufacturing sequence flow of the panel assembly line in way to reduce or eliminate the flow queues.

\subsection{First suggested sequence modification}

The first alternative on the panel assembly line sequence to be study aims to test the reliability of the "one-piece flow" concept on the several plates that form the panel, as suggested by Liker \& Lamb [3] and Kolich et al. [6], i.e., instead of assuming the panel as an individual product, consider it as a sum of multiple single products. Hence, the panel assembly line sequence would suffer a profound modification on its nature, thus displaying the following arrangement: Cutting of the correct perimeter of the steel plate, assembling of the stiffeners on the steel plate, welding of the stiffeners, and, finally, butt welding of the individual sets "plate + stiffeners", as shown in Figure 11.

\begin{tabular}{|c|c|c|c|c|c|c|c|}
\hline \multicolumn{8}{|c|}{ Modificated panel's line sequence } \\
\hline $\begin{array}{l}\text { Cut the perimeter on each } \\
\text { panel's plate, individually }\end{array}$ & \multicolumn{3}{|c|}{$\begin{array}{c}\text { Assembling the stiffeners } \\
\text { of each plate }\end{array}$} & \multicolumn{3}{|c|}{$\begin{array}{l}\text { Welding the stiffeners } \\
\text { of each plate }\end{array}$} & $\begin{array}{l}\text { Butt welding o } \\
\text { the plates }\end{array}$ \\
\hline-1 & 1 & 1 & 1 & I & I & 1 & \\
\hline $1-1$ & 1 & 1 & 1 & I & 1 & 1 & \\
\hline I & I & 1 & 1 & I & I & 1 & $s \quad \& \quad \neq$ \\
\hline 1 & 1 & 1 & 1 & । & & 1 & \\
\hline 1 & I & 1 & 1 & I & I & I & \\
\hline-1 & I & 1 & 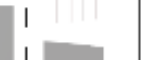 & & 1 & I & \\
\hline $\begin{array}{l}1 \\
1 \\
1\end{array}$ & ! & । & I & I & I & $\begin{array}{l}1 \\
1\end{array}$ & \\
\hline 1 & I & 1 & i & i & । & 1 & \\
\hline 1 & I & 1 & 1 & I & I & 1 & \\
\hline
\end{tabular}

Figure 11 First alternative on the panel assembly line sequence

PALIAN also includes the consideration of such panel assembly line sequence, and the respective obtained time chart of such manufacturing approach is illustrated in Figure 12. To correctly interpret the time chart is key to stress that each row and colour is associated with one given workstation: the first row, in red, represents the times of the plates cutting; the second row, in blue, represents the times of the stiffeners assembling on the plate; the third one, in green, illustrates the welding of the stiffeners; the last row, in yellow, exhibit the times of the butt welding of the panel's plates. Each colour's tint illustrates different panels, i.e., for example, in the third row, representing the stiffeners welding stage, the first four columns, with similar green tint, illustrates the four plates/sets of the first panel, and the 5th, 6th, 7th, 8th and 9th columns, with a brighter tint of green illustrates the five plates/sets of the second panel.

From the resultant hand-made value stream map illustrated in Figure 13, we get the following ratio:

$$
\frac{L T_{2}}{T A V_{2}}=\frac{48.16}{20.13}=2.39
$$

Although we have eliminated the queue before the $2^{\text {nd }}$ and $3^{\text {rd }}$ workstations, the conditional constrains of the $4^{\text {th }}$ workstation, where to butt weld the sets they need to be fully manufactured, generates vast gaps between the successive butt welds, thus increasing significantly the cycle time of the butt weld workstation, and thereafter increasing the lead time (LT) of the complete process. 
A fast and less correct analysis of the time chart obtained could lead us to consider that this alternative panel assembly line manufacturing sequence is better due to the $8 \%$ decrease of the total time needed to complete the four panels (from $81.4 \mathrm{~h}$ to $74.9 \mathrm{~h}$ ). The $37 \%$ increase of the ratio testified in eq. (2) strongly suggests that such solution would not be beneficial to the panel assembly line manufacturing process.

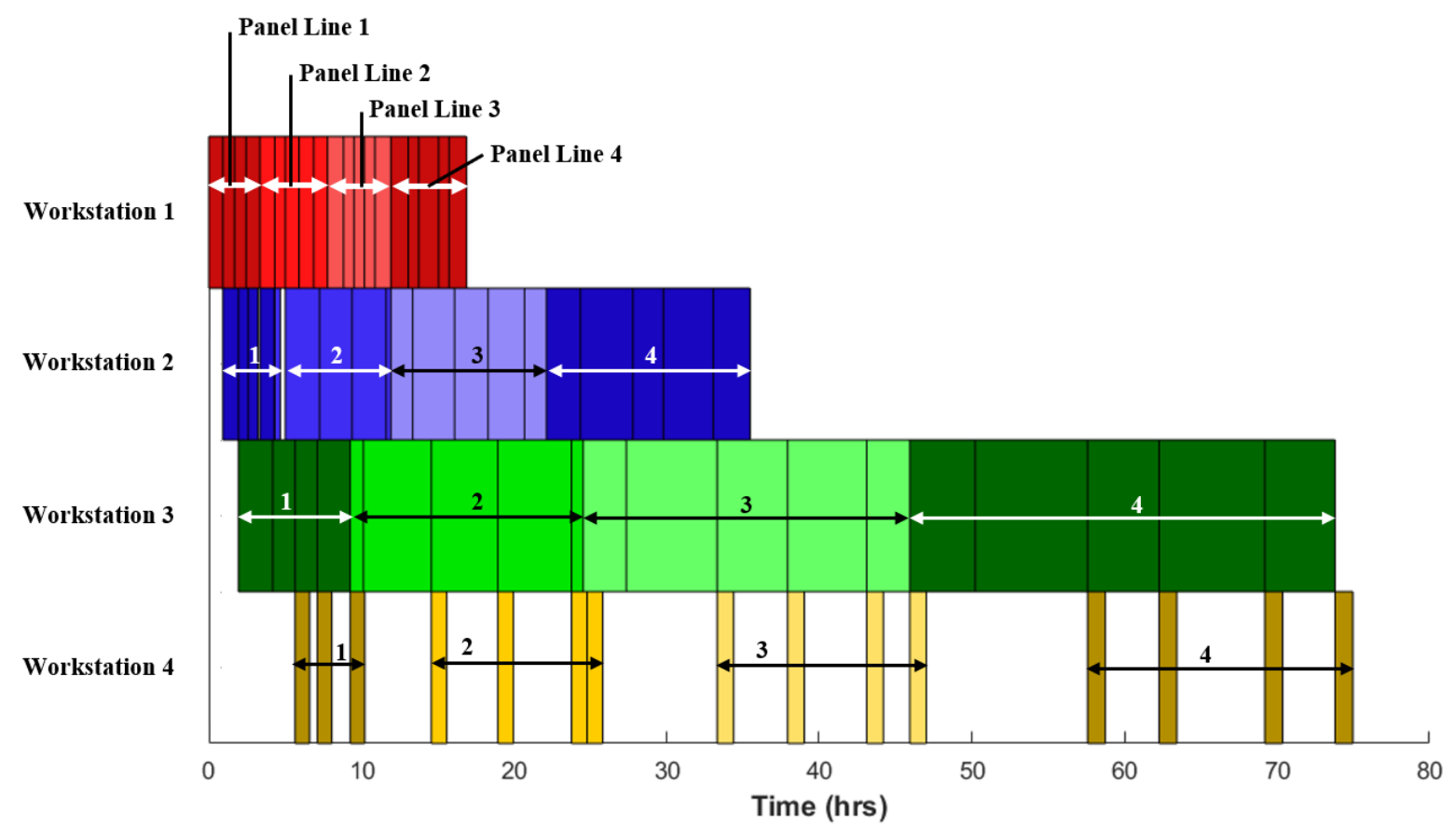

Figure 12 First sequence modification time chart

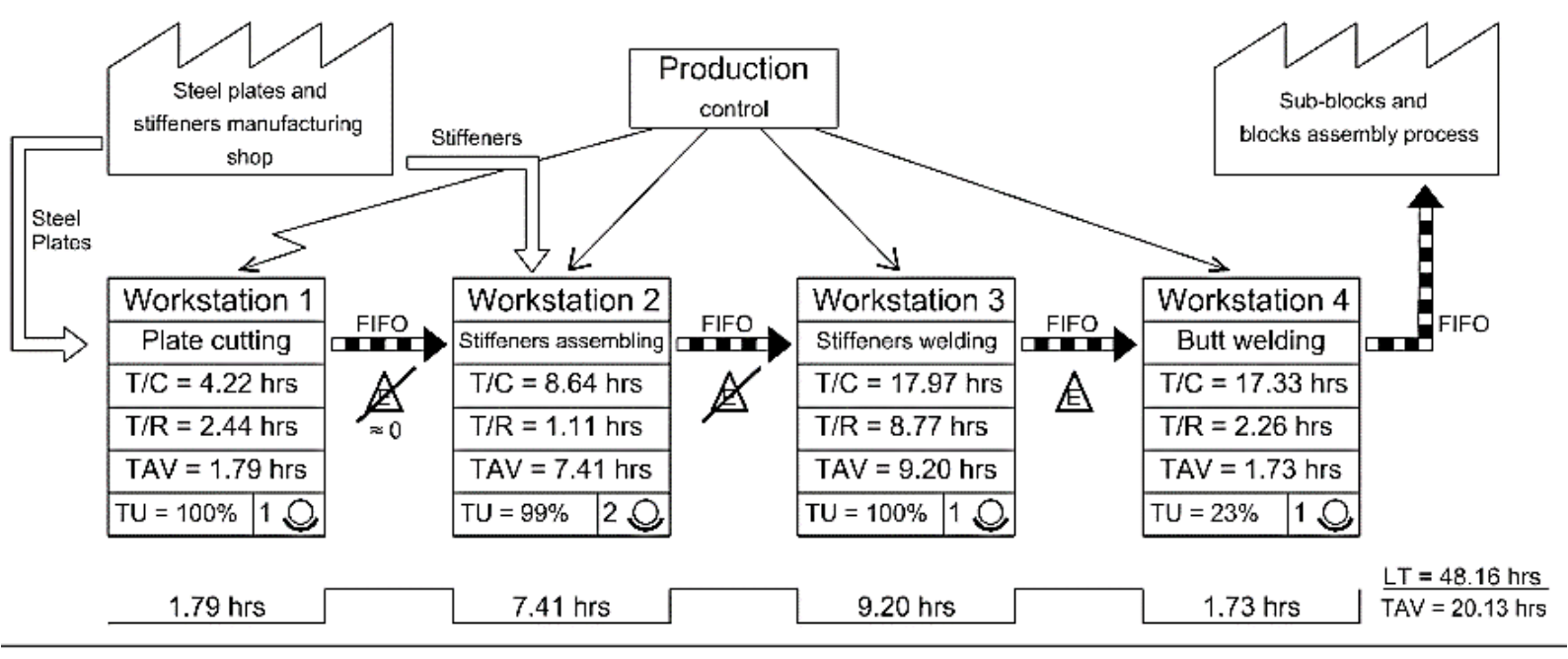

Figure 13 First sequence modification value stream map

\subsection{Second suggested sequence modification}

Analysis of Figure 13 suggests to join workstations 3 and 4. State of the art of actual equipments allows this merge between the butt welding of the profiles and its immediate fillet welding, as referred, for example, by Kolich et al. [5]. PALIAN supports such panel assembly line sequence possibility. The resultant time chart is presented in Figure 14, and, through its values, one can draw and compute the values of the respective value stream map, as shown in Figure 15. By merging the 3rd and 4th workstations, the queue times are eliminated, Figure 14, and the value stream map become: 


$$
\frac{L T_{3}}{T A V_{3}}=\frac{34.81}{20.13}=1.73
$$

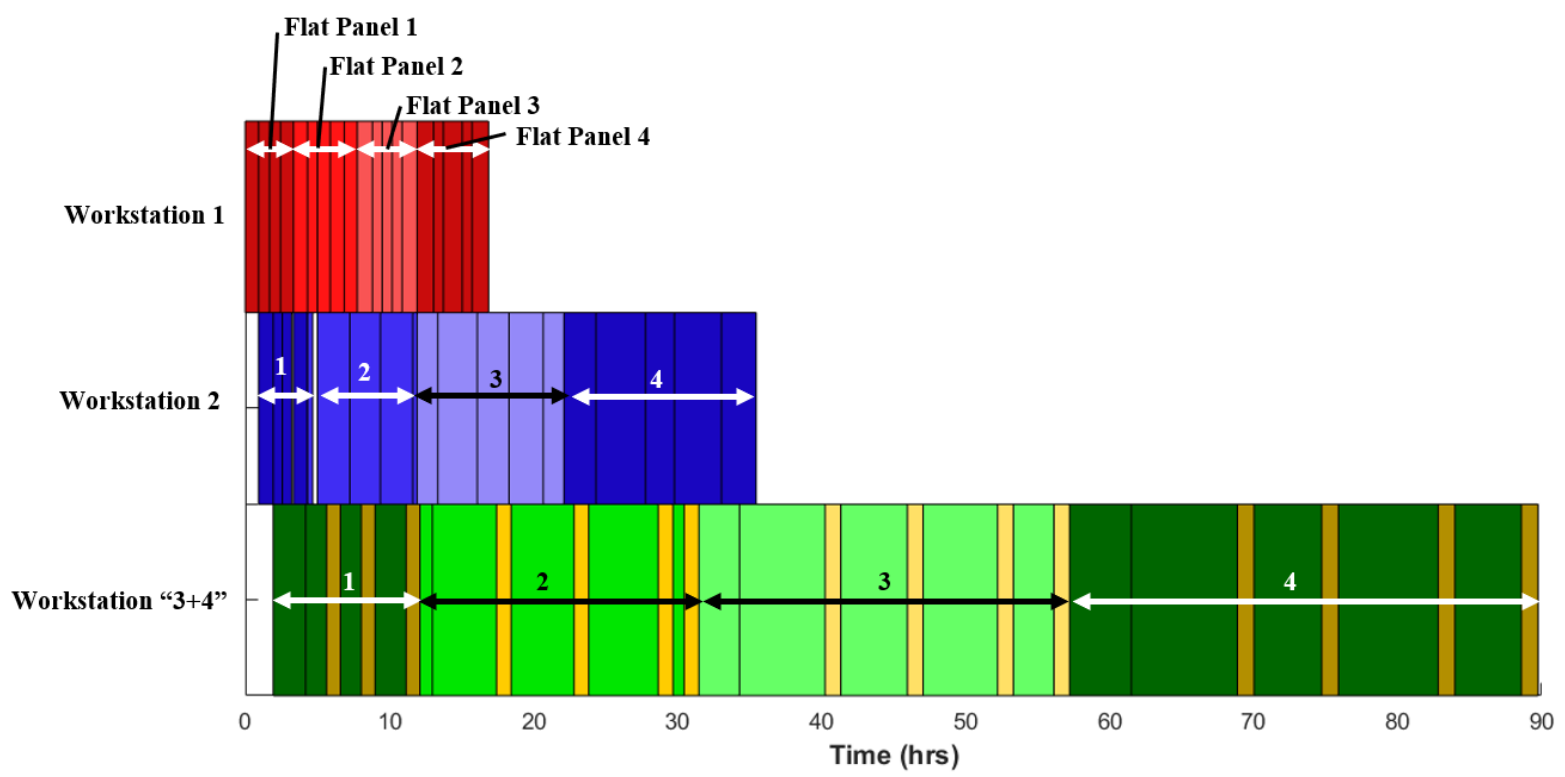

Figure 14 Second sequence modification time chart
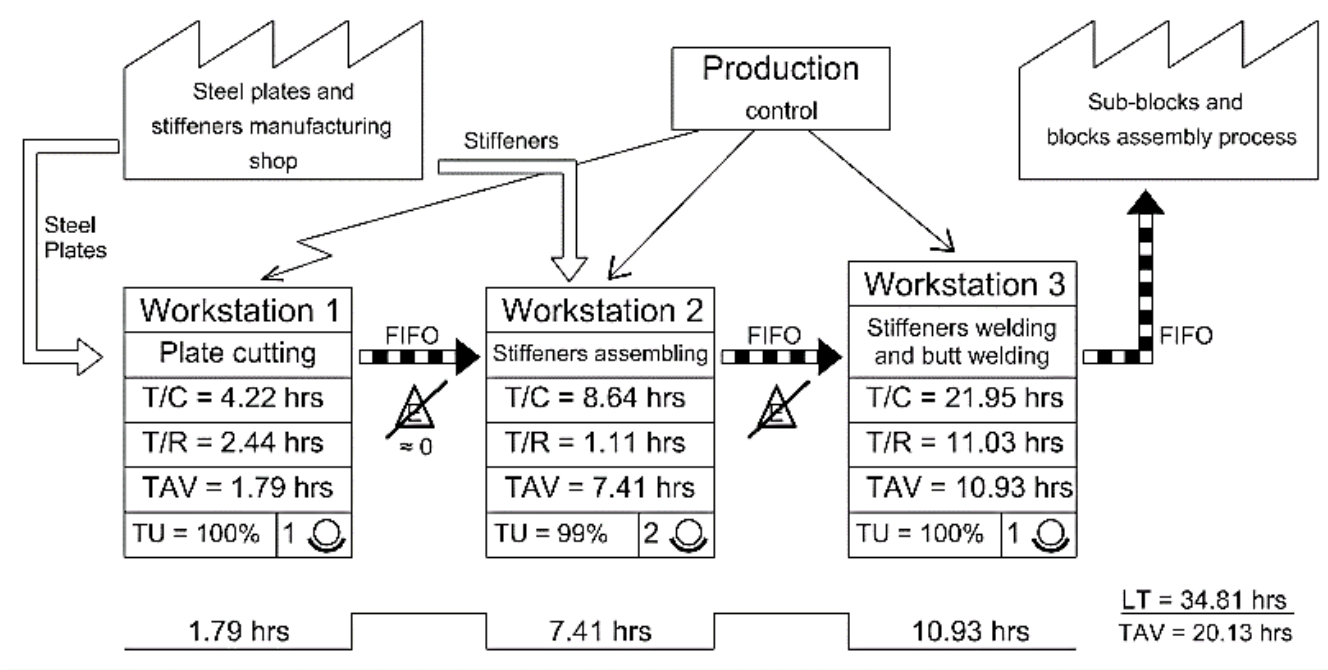

Figure $152^{\text {nd }}$ sequence modification value stream map

The ratio obtained is slightly smaller than the one of the original panel assembly line situation presented in formula (2), however the time needed to accomplish the complete manufacturing of all the four flat panels is $10 \%$ larger $(89.8 \mathrm{~h})$ than the time needed on the original panel assembly line, thus is interesting to realize a costs analysis comparison. As it was stated earlier, the developed program also computes the cost analysis of each panel assembly line workstation, which times are presented in Table 1 and 2.

The modified sequence situation presents no inactive labour cost, i.e., there is no flow queue in any workstation and thus no workers waiting for the product from the previous workstation. Using the concept of "plate + stiffeners" as main product instead of the panel as such, the changeover activities of the steel cutting station will be repeated more times. 
Instead of performing the cutting preparation, dimensional control and post cutting work activities only for the 4 panels, they will be repeated for the 19 plates of the four flat panels which generates an increase of the labour cost. Such supplementary activities generate a significant increase of the man-hours needed, thus increasing the labour cost on the steel cutting workstation. The savings of the modified sequence are, although positive, negligible, Table 1 and Table 2. The time needed to manufacturing of the four panels is $10 \%$ greater. One can conclude that the costs savings do not support the greater lead time of the manufacturing process.

Table 1 Original sequence cost analysis [€]

\begin{tabular}{lccc} 
Workstations & Consumables costs & Active labor costs & Inactive labor costs \\
\hline \hline Butt welding & 31.6 & 66.3 & - \\
\hline Plate blanket cutting & 14.7 & 50.7 & 30.0 \\
\hline Stiffeners assembling & 86.6 & 340.6 & 14.7 \\
\hline Stiffeners Welding & 234.5 & 431.2 & 7.1 \\
\hline
\end{tabular}

Table 2 Second sequence modification cost analysis [€]

\begin{tabular}{lccc} 
Workstations & Consumables costs & Active labor costs & Inactive labor costs \\
\hline \hline Plate cutting & 14.7 & 84.4 & - \\
\hline Stiffeners assembling & 86.6 & 340.6 & - \\
\hline Stiffeners welding & 234.5 & 431.2 & - \\
\hline Butt welds & 31.6 & 66.3 & - \\
\hline
\end{tabular}

\section{Overall Equipment Efficiency concept}

The Lean methodology focusses on the concept of the 7 wastes of the production process: 1. Transport; 2. Inventory; 3. Motion; 4. Waiting; 5. Over-processing; 6. Overproduction; 7. Defects.

Some of those wastes can be identified in the equipment-related activities, thus allow to list a set of other particular wastes related to the Overall Equipment Efficiency (OEE) as shown in Table 3 [10]. From the wide set of input data which the user should define in PALIAN, Figure 16, one can identify the OEE wastes listed in Table 4.

Considering the original panel assembly line process as the start reference point, by decreasing or eliminating the time values of some OEE wastes in an acceptable way (decrease, by half, the equipment setup time activities and considering that no re-welds are needed) Table 4 sums up the obtained values testifying the cost advantages of the implementation of production politics that lead to a decrease of the OEE wastes, such like the setup times or the re-works. The case study indicates a $10 \%$ reduction of the production cost and, simultaneously, the time needed to complete the four panels manufacturing process decrease by $19 \%$, from 81.4 $\mathrm{h}$ to $66.2 \mathrm{~h}$. 


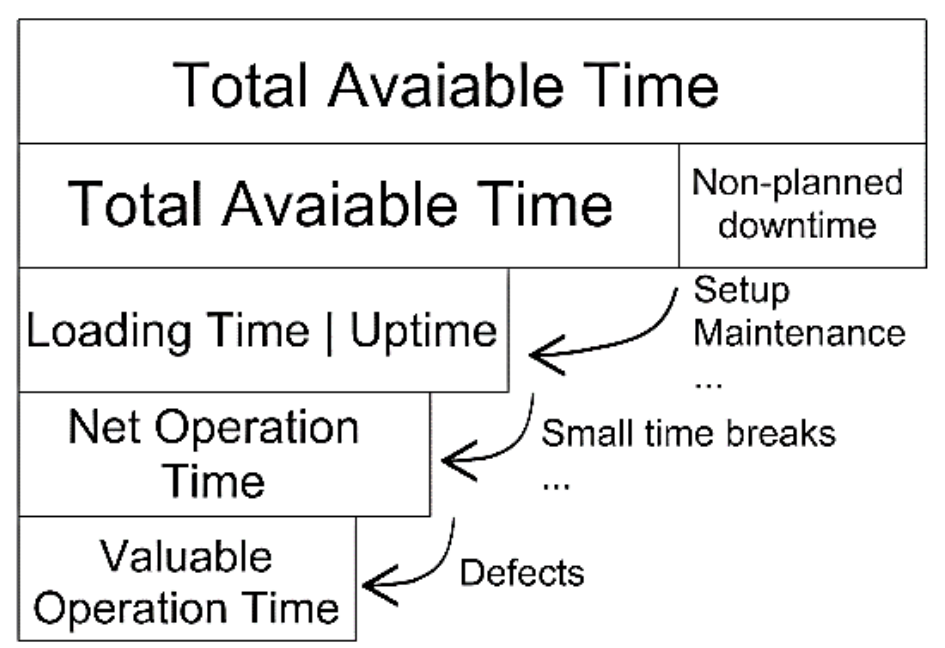

Figure 16 OEE analysis wastes [10]

Table 3 OEE wastes specified in the input interfaces

\section{Butt welding workstation}

Welding preparation

Tag-welding preparation

Re-welding

Plate blanket cutting workstation

Automatic cutting equipment setup

Stiffeners welding workstation

First side welding preparation

Second side welding preparation

Welding equipment preparation

Re-welding

Table 4- OEE wastes improvement costs analysis

\begin{tabular}{lccc} 
Workstations & Consumables costs & Active labor costs & Inactive labor costs \\
\hline \hline Butt welding & 28.7 & 52.4 & - \\
\hline Plate blanket cutting & 13.7 & 48.2 & 18.1 \\
\hline Stiffeners assembling & 86.6 & 340.6 & 5.3 \\
\hline Stiffeners Welding & 227.3 & 341.5 & 10.4 \\
\hline
\end{tabular}

\section{CONCLUSIONS}

The results obtained and analysed allowed to testify that the appropriated product to consider in the "one-piece flow" methodology is the flat panel, instead of the "plate + stiffeners" sets that compose the flat panel. For such analysis, the value stream mapping of the manufacturing process was a key element to interpret the production efficiency, proving the reliability of Lean methodology analysis tool. 
By considering the "7 deadly wastes" described by the Lean methodology, and applying them to the OEE, thus suggesting the equipment-related activities which times should be decreased or eliminated, allowed to obtain significant cost and time advantages on the panel assembly line manufacturing process. Such improvements could be obtained by installing newer equipment and higher quality welding technologies.

\section{Acknowledgements}

The paper was performed in the scope the project "Ship Lifecycle Software Solutions", (SHIPLYS), partially financed by the European Union through the Contract No 690770 SHIPLYS - H2020-MG-2014-2015.

\section{REFERENCES}

[1] Gordo, J.M., Carvalho, I., \& Guedes Soares, C. (2006). Potencialidades de processos tecnológicos avançados de corte e união de aço em reparação naval. Inovação e Desenvolvimento nas Actividades Marítimas, pp. 877-890.

[2] Ohno, T. (1988). Toyota production system: beyond large-scale production.

[3] Liker, J., \& Lamb, T. (2002). What is lean ship construction and repair. Journal of Ship Production. 18(3):121-142.

[4] Storch, R., \& Lim, S. (1999). Improving flow to achieve lean manufacturing in shipbuilding. Production Planning and Control. https://doi.org/10.1080/095372899233280.

[5] Kolich, D., Fafandjel, N., \& Zamarin, A. (2012). Lean manufacturing methodology for shipyards. Brodogradnja. 63(1), 18-29.

[6] Kolich, D., Storch, R., \& Fafandjel, N. (2017). Lean methodology to transform shipbuilding panel assembly. Journal of Ship Production and Design. 33 (4):317-326. https://doi.org/10.5957/JSPD.160028.

[7] Leal, M., \& Gordo, J.M. (2017). Hull's manufacturing cost structure. Brodogradnja/Shipbuilding, 68(3):1-24. https://doi.org/10.21278/brod68301.

[8] Oliveira, A., \& Gordo, J.M. (2018). Implementation of new production processes in panel's line. Maritime Transportation and Harvesting of Sea Resources. Lisbon: Taylor \& Francis Group.

[9] PALIAN, Panel Assembly Line Analysis software, ShipLYS, 2017.

[10] Gibbons, P. (2006). Improving overall equipment efficiency using a Lean Six Sigma approach. In Int. J. Six Sigma and Competitive Advantage, 2, 207-232. https://doi.org/10.1504/IJSSCA.2006.010110.

Submitted: $\quad$ 18.07.2018. André Oliveira, andre.lopes.oliveira.1@gmail.com José Manuel Gordo, jose.gordo@centec.tecnico.ulisboa.pt

Accepted: $\quad 31.10 .2018 \quad$ CENTEC, Instituto Superior Técnico, Av. Rovisco Pais, 1049-001 Lisboa, Portugal 